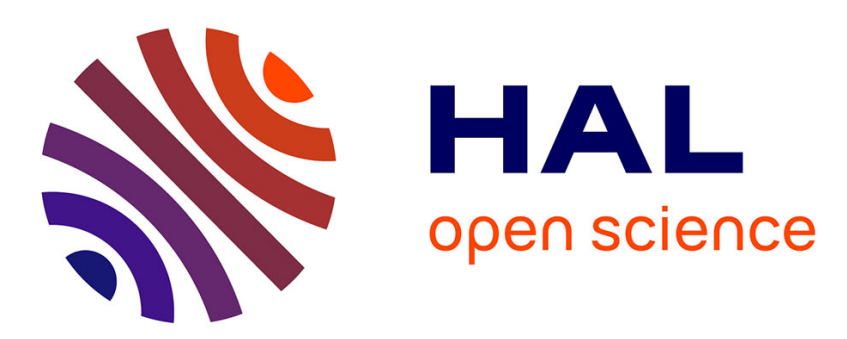

\title{
OPTICAL GENERATION OF ULTRASONIC WAVES BY THE TRANSIENT GRATING METHOD: APPLICATION TO ACOUSTIC PROPERTY MEASUREMENTS
}

R. Casalegno, M. Pierre

\section{- To cite this version:}

R. Casalegno, M. Pierre. OPTICAL GENERATION OF ULTRASONIC WAVES BY THE TRANSIENT GRATING METHOD: APPLICATION TO ACOUSTIC PROPERTY MEASUREMENTS. Journal de Physique Colloques, 1987, 48 (C7), pp.C7-533-C7-535. 10.1051/jphyscol:19877127 . jpa00226946

\section{HAL Id: jpa-00226946 https://hal.science/jpa-00226946}

Submitted on 1 Jan 1987

HAL is a multi-disciplinary open access archive for the deposit and dissemination of scientific research documents, whether they are published or not. The documents may come from teaching and research institutions in France or abroad, or from public or private research centers.
L'archive ouverte pluridisciplinaire HAL, est destinée au dépôt et à la diffusion de documents scientifiques de niveau recherche, publiés ou non, émanant des établissements d'enseignement et de recherche français ou étrangers, des laboratoires publics ou privés. 
JOURNAL DE PHYSIQUE

Colloque C7, supplément au $\mathrm{n}^{\circ} 12$, Tome 48 , décembre 1987

OPTICAL GENERATION OF ULTRASONIC WAVES BY THE TRANSIENT GRATING METHOD : APPLICATION TO ACOUSTIC PROPERTY MEASUREMENTS

R. CASALEGNO and M. PIERRE

Laboratoire de Spectrométrie Physique, associé au CNRS et Celphyra, Université Scientifique, Technologique et Médicale de Grenoble, BP 87, F-38402 Saint-Martin-d'Hères Cedex, France

ABSTRACT: Efficient production of coherent phonong by spatially periodic impulsive heating is shown to be a very well established method and to give reliable measurements of strong acoustic attenuation. Special care is taken to eliminate size effects. The technique is applied to a polymer material undergoing a glass-rubber phase trangition.

\section{INTRODUCTION:}

The basic principles of the method have already been developped elsewhere in this issue $/ 1 /$ as well as the mechanisms involved in the acoustic wave generation $/ 2 /$. We used impulsive heating rather than stimulated Brillouin scattering in order to get a efficiency of several orders of magnitude higher in the sound wave production. impulsive generation is obtained if heat deposition is performed in a time short compared to the acoustic wave period. This was realized by doping the material with a suited dye /3/. The method was shown to be particularly well adapted for situations where conventional methods fail. especially when the acoustic attenuation becomes very gtrong. The study of a polymer undergoing a glass-rubber phase transition is a good example. The oscillatory time behaviour of the diffracted signal gives unambiguously the acoustic period $T$. On the contrary it is much more difficult to extract precise values of the acoustic attenuation due to finite size effects.

\section{INFLUENCE OF FINITE SIZE EFFECTS:}

The relation commoniy used to calculate the acoustic attenuation $\alpha$ from the diffraction efficiency $\delta$ is

$$
\delta(t)=A|\Delta n|^{2}=B[1-\exp (-\alpha t) \cdot \cos (2 \pi t / T)]^{2}
$$

where $n$ is the refractive index. This relation contains the following hypothesia:

i) the heating time is assumed to be much shorter than $T$ and taken as a Dirac peak.

ii) the plane wave approximation is valid. 


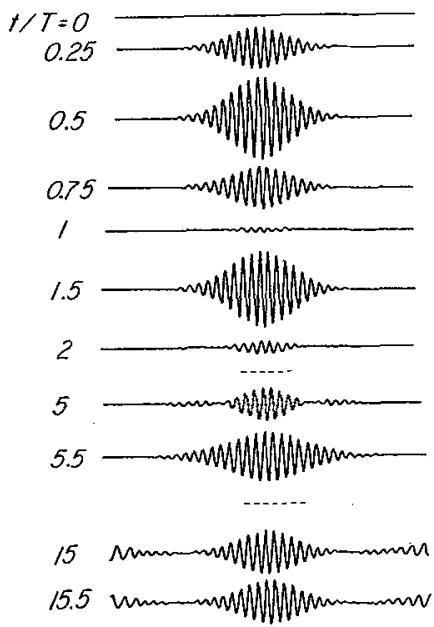

Fig.1.

Variation of the refractive index $n(x, t)$ with position (horizontal and time (vertical) around its equilibrium value.

Fig. 2 .

Typical record for PMMA at room temperature.

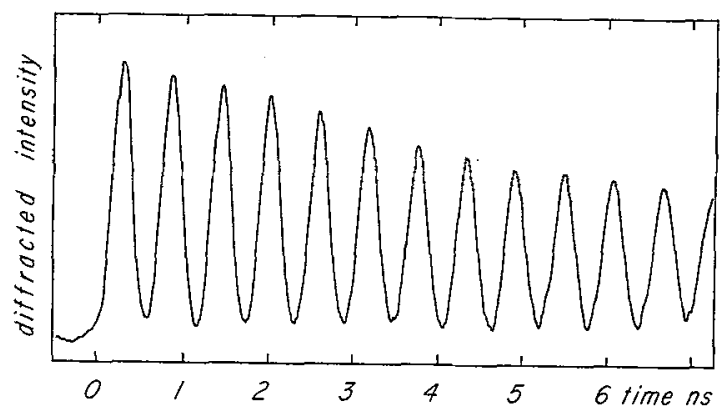

The first hypothesis is satisfied if the pulse duration and the dye relaxation time are much shorter than $\Lambda / v$ ( $\Lambda$ is the fringe spacing, $v$ the speed of sound). This condition is oasily fulfilled. The second hypothesis is much more difficult to satisfy as it requires very large beam waists, thereby reducing the light intensity and the sound wave production efficiency. The finite gize of the laser beams has an effect illustrated by the Fig.1. If showg the variations of the refractive index $n(x, t)$ both with position and time around itg equilibrium value. $n(t)$ must be taken as an average value of the difference between the value of the index at a maximum and the value at the neighboring minimum. The signal is proportional to I $\left.n(t)\right|^{2}$. In the central region (explored by the probe impulsion) it is oscillating with a decreasing amplitude and finally constant ( for $t / T>15$, although the two counterpropagating acougtic waves visible on the sides are not completely damped out. This effect must be eliminated in order to avoid surestimated attenuation. The propagation effect will be negligible for strong attenuations $i . \theta$. when $1 / \alpha \ll \Phi / v$ where $\Phi$ is the laser beam diameter in the sample. 


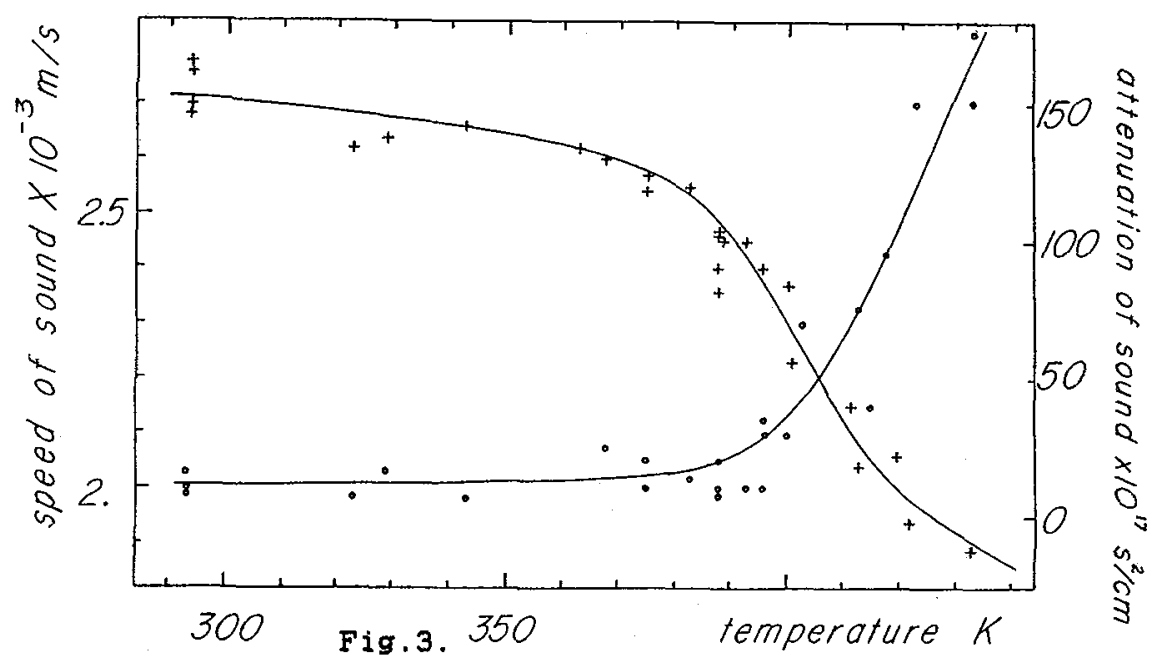

Variation with temperature of acoustic properties of PMMA:

+ apeed of hypersonic $(\approx 1.5 \mathrm{GHz})$ wave (left),

o attenuation of hypersonic wave (right).

\section{EXPERIMENTAL:}

Description of the experimental setup and materials are available in ref.3. One supplementary information will concern the laser beam radii which were aet at $100 \mu$ for the excitations and $50 \mu$ for the probe with a fringe spacing of $\Lambda=1.6 \mu$.

\section{DATA ANALYSIS AND RESULTS:}

Expression (1) shows that at times $t=(2 p+1) T / 4$ (p integer) there is no acougtic effect and the corresponding points allow the definition of a reference line. In order to calculate the attenuation it is necessary to plot the guccessive maximum valueg of $\delta$ versus $t$ and take the slope at tmo: this eliminates the finite size effects. On Fig. 2 . is a typical record for a PMMA sample at room temperature. From records at various temperatures the curves of Fig.3. are obtained. These curves clearly exhibit a large variation of the speed of sound going from $2700 \mathrm{~m} / \mathrm{s}$ at room temperature to less than $1900 \mathrm{~m} / \mathrm{s}$ above the transition temperature $(378 \mathrm{~K})$. Much more remarkable is the growth of the attenuation of gound defined as $\alpha / v f^{2}$ ( $f$ is the sound frequency) by two orders of magnitude for $f * 1.7 \mathrm{GHz}$. Thig means that the amplitude of the sound wave is divided by $\theta$ after only three oscillations.

/1/ R. Casalegno, previous communication.

/2/ K.A.Nelson, R.J.Dwayne Miller and M.D.Fayer. J.Appl. Phys. 53 (1982) 1144.

/3/ D.Blanchard, R.Casalegno, M.Pierre and H.P.Trommsdorff. Proceedings of DPC July 1987, J.Physique C7 (1985) 517. 